\title{
The Effect of Using the Differentiated Education Strategy on Achievement in Mathematics among Basic Elementary School Students in Jordan
}

\author{
Dr. Talal Yousef Abu Amara \\ Royal Jordanian Air Force Technical University College for Aviation Sciences RJAFC
}

\begin{abstract}
This study aimed to investigate the effect of using the differentiated education strategy on mathematics achievement among ninth grade students in Jordan. The number of the study members was (106) male and female students, who were divided into two groups: the first is an experimental group that studied using the differentiated education method consisting of (24 male and 18 female students), and the second is a control group that studied in the traditional way consisting of (39 male and 25 students). The study plan of the experimental group included Geometry unit topics that were designed using the differentiated education strategy. An achievement Exam was done in the Geometry unit and it was judged, The values of honesty and reliability has been calculated, and the results of the study showed that there are statistically significant differences at the level of $(\alpha=0.05)$ between the students 'grades in Mathematical Achievement due to the teaching method used for the benefit of the experimental group that studied in a method Differentiated Education, and the absence of statistically significant differences at the level of $(\alpha=0.05)$ between students 'grades in achievement rates attributable to the gender variable, as well as the absence of a statistically significant interaction between the teaching method and gender.
\end{abstract}

Keywords:

differentiated education strategy, achievement, ninth grade.

Article Received: 18 October 2020, Revised: 3 November 2020, Accepted: 24 December 2020

\section{Introduction}

The development in the different fields of life has accompanied it with a great development in the educational field which always seeks to develop teaching methods, evaluation and activities in line with the nature of the knowledge content of the subject, and the various levels of knowledge of students, which is reflected positively on the performance of students, and the educational field is considered one of the constantly developing fields The result of dozens of studies and research in all relevant educational fields.

Teaching methods are considered the teacher's work in which he determines the expected learning outcomes, and uses the planned processes, activities and means that aim to develop students' skills and provide them with various cognitive and emotional outcomes after they have gone through the learning experience in the classroom. despite the diversity in teaching methods, some mathematics teachers still complain about difficulties in applying them for various reasons, so there is still an urgent need for the mathematics teacher to use teaching methods that they master and meet the needs of students and their families in a better understanding of the mathematical content that is reflected in good performance in the students 'results and achievement.

The diversification of teaching methods is based on the teacher's ability to face differences between students within the class without isolating gifted students from students with medium or low achievement because the students we teach do not learn in one way, but rather there are multiple individual differences and differences between them that affect their desire for a type. Appropriate education for them according to their ability and speed of learning. (Al-Rehaily, 2012) 
Al-Barakati (2018) explained that the process of renewal and modernization in the field of teaching methods and strategies, especially in mathematics, is no longer a field of discussion, but rather has become an urgent matter in order to strike a balance between a rapidly changing life and the role that educational institutions and their systems should play as these days witness a widening gap, between the educational needs of students and the professional abilities of teachers, as the need to develop students 'skills in research, investigation, criticism, active listening and discipline increases, so it is necessary to diversify teaching methods that present mathematics as an essential part of the changes in the current era and increase students' ability to solve problems in an academic atmosphere that prevails Fun and fun contribute to their enthusiasm and increase their motivation to learn mathematics

Differentiated Instruction is considered one of the teaching strategies concerned with raising the performance levels of all students in the class and not a specific group of them, Teachers take into account a set of student's personal characteristics, preferences, motivation, various accumulative experiences and their level of achievement when building the necessary teaching tools. (Rahma, 2017)

\section{Differentiated Education:}

Tomlinson (2016) defined Differentiated Education as the teacher's response to the diverse learning needs of students in the classroom, while both (Obaidat and Abu Al Sameed ,2007) defined it as education aims to raise the level of achievement of all students in the class and not the group of students who have problems in achievement according to multiple criteria, including: the individual's previous experience, characteristics, abilities, and trends towards the subject according to the teachers' vision and expectations of those students.(Kojak et al, 2008) defined Differentiated Education as: Knowing the different needs of learners: previous information willingness to learn, linguistic level, preferences, and preferred learning styles, and then responding to all of that in the process of teaching diversification that takes into account the teaching and learning processes of students who have multiple differences in one classroom.

Campbell (2008) defined Differentiated Education as: a series of procedures used to teach students whose abilities differ in one classroom with aim of improving the achievement of each student, while Lutfi (2012) defined it as a teaching approach based on identifying the various educational needs of learners and their readiness to learn and define their interests responding to these differences in needs, preparations and interests through the elements of the teaching process, so that the teaching elements are differentiated to meet the differentiation and difference of learners within the same classroom, in order to provide all with equal opportunities for learning to occur.

\section{Foundations of Differentiated Education:}

(Kojak et al., 2008) mentioned a set of foundations on which the Differentiated Education strategy is based, including:

Legal Foundations: As the education of the individual is one of the rights recommended in human rights documents, regardless of his gender, nationality, mental, social and economic level.

Psychological Foundations: There are individual differences between individuals. Each individual has various capabilities in learning according to his motivation, tendencies, type of intelligence, and the extent of his readiness to learn, define his interests, respond to these interests and develop them.

Pedagogical Foundations: The student is the focus of school work, and the teacher is the facilitating leader who takes into account the simplification of the knowledge material, and the design of activities, teaching methods and appropriate evaluation that aim to achieve learning among students with similar levels of performance. 
Forms of Differentiated Education:

(Obeidat and Abu Al-Sameed, 2007) and (Zaitoun, 2003) mentioned a number of distinct forms of education, namely:

(1) Teaching according to the theory of multiple intelligences (Gardner's classification: linguistic, logical, spatial, visual, musical, social, subjective, contemplative and natural intelligence), where groups are divided according to the type of intelligence of each learner (logical intelligence, linguistic intelligence, ...) and teaching is designed according to these intelligences.

(2) Teaching by means of cooperative learning (dividing students into homogeneous groups according to their preferences, learning style, or different intelligences, in order to achieve learning objectives).

(3) Teaching according to the styles of the learners (some educational psychologists classify the types of learners into auditory, visual, and kinesthetic styles, and some add a sensory pattern), where teaching takes place according to the appropriate pattern for each student.

(Kojak et al., 2008) mentioned a set of effective strategies in Differentiated Education, including: learning pillars and resources strategy, curriculum content pressure strategy, progressive activities strategy, Case study strategy, Flexible group strategy, Learning contract strategy, Fixed activities strategy, problem-solving strategy ,Think Pairing Strategy Share.

\section{Importance of Differentiated Education:}

The importance of using the Differentiated Education strategy is highlighted in that it takes into account the individual differences between students in the classroom and works to increase the academic achievement of all students, increase their motivation towards learning, and works to build their self-confidence through success in completing the tasks that they see distinct and difficult, and the good use of the strategy Helps the teacher to improve the classroom management, and increase his experience in diversity by using different teaching methods and evaluation.

(Al-Mahdawi, 2014) mentioned some of the points indicating the importance of Differentiated Education, including:

- Differentiated Education works to satisfy and develop different tendencies and trends, and enhances the student's level of motivation.

- It takes different learning styles, such as: auditory, visual, logical, social, and sensory.

- Works to develop innovation and encourages creativity among students.

It is based on enhancing integration between the different strategies of education.

- Achieves various effective learning conditions.

- Provides equal opportunities for all students to learn, each according to his abilities and inclinations.

- It improves teachers' skills in teaching and evaluation.

\section{The Goals of Differentiated Education:}

The Goals of Differentiated Education summarized by (Al-Helisi, 2012) and (AlMahdawi, 2014) as follows:

- Providing opportunities for students to work according to different teaching methods to teach content.

- Developing various educational activities based on analyzing topics and analyzing content into core concepts, processes and important skills.

- Design various educational situations and tasks based on the necessary and basic concepts and skills.

- Compatibility of standards and curriculum requirements for each learner.

- Responding to the different levels of readiness and teaching needs of students, developing their motivation towards learning, and taking into account the individual differences between them

- Developing tasks that achieve the challenging mission of each student.

- Work on harmony and positive interaction between the student, the focus of the teaching 
process, and the teacher who facilitates that process

\section{Fields of Differentiation in Education:}

(Al-Tuwairqi, 2013) and (Kojak, 2008) classified the areas of differentiation in education in three fields :

- The field of Goals: where the teacher sets cognitive goals according to the student's level of knowledge.

- The field of Teaching Methods: the teacher chooses the method and style of teaching the student according to the knowledge position.

- The field of Outputs: where the educational outcomes differ according to the student's knowledge level

Ali Akbari and Jaber (Aliakbari \& Jaber, 2014) classify the differential elements of education into:

- Learning Content: It includes the scientific material, concepts, principles, skills, activities and methods used in teaching to achieve the objectives of learning processes.

- Processes: This includes how content is taught and distributed to cooperative learning groups.

- Outcomes: the behavior expected to occur in the student after going through the learning experience, after using appropriate evaluation methods that indicate the occurrence of learning

\section{Differentiated Education Steps:}

Tomlinson (2013) and (Obeidat and Abu AlSameed, 2007) mentioned differentiated teaching steps that a teacher is supposed do as follows:

- The teacher determines the information, capabilities and competencies that each learner has before starting the learning process.

- He classifies his students into homogeneous groups with roughly the same level and characteristics.

- He specifies precisely the learning outcomes to be achieved by the student after going through the learning experience.
-He identifies the materials, activities, teaching strategies, evaluation, teaching tools and learning resources needed for each group.

- He organizes the educational environment in the classroom to suit the work of those groups in an easy way.

- Also the teacher defines the tasks required to be performed by each group, and the learning outcomes to be achieved.

\section{The Disadvantages of using Differentiated}

Education Teaching Method :

(Attia, 2009) listed some of the disadvantages of Differentiated Education, including:

- The necessary need for a teacher with a high teaching abilities.

- The need for elaborate and accurate teaching plans suitable for each class of learners. - The teacher may not organize the appropriate environment for the classroom in a way that suits the scientific material.

- Some teachers, supervisors and school principals are not aware of the goals of this method because they are accustomed to applying traditional methods of teaching.

\section{The Role of the Student in Differentiated}

\section{Education:}

(Kojak et al., 2008) summarized a set of these roles as follows:

- That the student knows the goals of the learning process, and his tasks that he must perform.

- The student has positive obligations towards the learning group to which he belongs and is keen to do them.

- The student accepts the idea of different tasks and activities that the teacher presents to some of his colleagues, and does not consider it deficient in his right.

- The student gets used to diversifying teaching methods and evaluating them according to different topics. 


\section{The Study Problem:}

The problem of the current study was identified in the low level of achievement of ninth grade students in mathematics, in addition to their poor performance in solving Geometric problems, and this decline is due to many reasons, including the nature of the curriculum used, the student's abilities and interests, the teaching and evaluation methods used by the teacher, and following up on parents. ..etc.

The results of the Iinternational Study Tests in Science and Mathematics (TIMMS, 2015), in which Jordan participated, indicated that it had obtained the position (36) in the field of mathematics out of (49) countries of the world, where Geometric had a prominent place in this exam and occupied the percentage of $20 \%$ of the mathematics test, and the average scores of Jordanian students were lower than their averages in previous years, as it appears that there is an urgent need for reviewing mathematics curricula, programs for preparing teachers, and the school environment in general to introduce the necessary improvements to the international level that we need to achieve. (National Center for Human Resources Development, 2017).

From the researcher's point of view, the teaching strategy that mathematics teachers follow in teaching mathematics concepts, including Geometric concepts, is one of the important factors that may cause this decline, as this decline was diagnosed through many indicators that the researcher touched through his long experience in the field of supervising Teaching mathematics and supervising master's theses, as he noticed the students 'reduced ability to recognize and understand mathematical concepts, especially those related to Geometric and the weakness in their expression, as well as the results of public examinations, research and studies conducted in the Jordanian environment and the results of the National Center for Human Resources Development, which indicated the low levels of Achievement in mathematics in general reinforces the view that there is a problem in students 'achievement in mathematics.

Therefore, this study attempts to identify the effect of using the Differentiated Education strategy on achievement in mathematics (Geometry unit) among ninth grade students in Jordan.

\section{Study Questions and Hypotheses:}

The problem of the study lies in the following main question: What is the Effect of Using (Differentiated Education strategy and the Usual Method of Teaching) on Achievement in Mathematics? It resulted in the following three questions:

The First Question: Are there Differences between the Averages of Ninth Grade Students Achievement in Mathematics According to the Using Different Teaching Strategies (Differentiated Teaching and the Usual Method)?

The Second Question: Are there Differences between the Averages of Ninth Grade Students Achievement in Mathematics According to gender (Male and Female)?

The Third Question: Is there an Effect of the Interaction between Teaching Strategies and Gender on Ninth Grade Achievement in Mathematics?

\section{Study Hypotheses:}

The First Hypothesis: There are no statistically significant differences (at $\alpha=0.05$ ) between the averages of ninth grade students 'achievement in mathematics due to the difference between teaching strategies (Differentiated Teaching, the Usual Teaching Method)

The Second Hypothesis: There are no statistically significant differences (at $\alpha=0.05$ ) between the averages of ninth grade students 
'achievement in mathematics due to the difference in sex (male and female)

The Third Hypothesis: There are no statistically significant differences (at $\alpha=0.05$ level) due to the presence of interaction between teaching strategy and gender in ninth grade students 'achievement in mathematics.

\section{Previous Studies:}

- Ariss (2017) conducted an exploratory study on a sample of 30 male and female students from one of the mathematics classes at the secondary stage of the University of Toledo, where the study aimed to identify the expected performance of students after passing through Differentiated Education experience through their academic achievement in algebra And their feelings towards the method of teaching in this way, and the researcher used Differentiated Education strategy methods in teaching advanced algebra, and this included reorganizing and presenting content in a way that suits students' levels, daily preparation, teaching tools, evaluation methods, worksheets, duties and roles, In analyzing the results, the researcher used qualitative research methods such as: observation, direct observation, analysis of documents, interviews, and various reactions. Quantitative methods were used, such as: short, regular and final exams, and a questionnaire, and the study concluded that the use of the Differentiated Education strategy in teaching increased students 'achievement in algebra, and all students' reactions were positive and feel satisfied with the academic content, teaching methods and evaluation.

- (Rahma, 2017) conducted a study entitled the effect of employing differentiated teaching on developing mathematics skills and the trend towards them, as the study sample consisted of 70 female students of the eighth grade in a Gaza school, and they were divided into two experimental groups that studied in a differentiated teaching method, and a control group. The researcher tested mathematics skills and an attitude toward mathematics scale, and the results of the study indicated the existence of statistically significant differences in favor of the experimental group that studied the Differentiated Education method in mathematics skills, and the absence of statistically significant differences between the two groups in the attitudes toward mathematics scale.

- Each of (Al-Ali and Al-Mahrezi, 2017) conducted a study that aimed to investigate the effect of using the Differentiated Education strategy in teaching mathematics on the achievement of the eighth grade basic students in the unit of relative numbers and the development of self-concept (the academic dimension). The study sample consisted of (95) Students in Hajjah city in Yemen, divided into two experimental and control groups, and the study concluded that the use of Differentiated Education strategy in teaching mathematics has an effective impact on improving students 'achievement and achieving their selfconcept.

- (Al-Nabhan, 2016) conducted a study aimed at identifying the effectiveness of teaching using the educational pillars and Differentiated Education strategies in the achievement of second-grade intermediate students in the subject of physics. The study was applied to a sample of (88) students from a school in the city of Diwaniyah in Iraq. Divide them into three 
groups, two experimental groups, one of which was taught using the educational pillars strategy, the second using the Differentiated Education strategy, and the third a control group in the traditional way. The researcher prepared a multiple-choice achievement test consisting of (40 items), and the results showed statistically significant differences between the averages of achievement degrees in the subject of physics between students of the two experimental groups and students of the control group and in favor of students of the two experimental groups. Students of the two experimental groups.

- (Morsi, 2015) conducted a study on the effectiveness of the differentiated teaching approach in science education on developing scientific concepts and the trend towards science among elementary school students in the Kingdom of Saudi Arabia. The researcher prepared a test that measures the extent to which pupils acquire scientific concepts and a measure of pupils 'attitudes toward learning science. From their sincerity and consistency, the study was applied to (40) students of the fifth grade in Jizan governorate, after dividing them into two groups: experimental and control, and the results of the research indicated the effectiveness of the differentiated teaching approach in developing scientific concepts among students of the experimental group compared to the results of the control group. And the ineffectiveness of the differentiated teaching approach in developing the attitude towards science among the pupils of the experimental group, in a way that is indicative of the control group students.

- As for (Al-Raei, 2014), he conducted a study entitled Effectiveness of
Differentiated Education Strategy in Teaching Mathematics on the acquisition of mathematical concepts and the tendency towards mathematics of the seventh grade basic student, where he used a test for mathematical concepts of the group unit that he prepared, and a measure of students 'tendency towards mathematics. The study was applied to 80 students in one of the Gaza schools, the students were divided into two experimental groups that studied differentiated teaching method, and a control group studied in the usual way, and the results showed that there were statistically significant differences in testing mathematical concepts in favor of the experimental group and the presence of statistically significant differences in the inclination scale Towards mathematics in favor of the experimental group.

- Al-Mahdawi (2014) conducted a study aimed at identifying the effect of using the differentiated teaching strategy on academic achievement at higher cognitive levels: analysis, synthesis, evaluation, and cognitive achievement as a whole in the biology course of secondary school students in Al-Leith governorate. Where the sample was divided into two experimental groups that were taught using the differentiated and controlled teaching strategy in the usual way, and the study population may consist of (730) students. (50) students were chosen by the intentional method, and the results of the study showed a statistically significant difference between the average scores of students in the main paragraphs. At higher mental levels in favor of the experimental group that studied using the differentiated teaching strategy.

- Joseph (2013) study on trained teachers from more than one specialization where 
the study population consisted of (379) male and female teachers classified into the two categories of trainee teacher and teacher working in education from the city of Trinidad in the Republic of Trinidad and Tobago in South America, and the study tool was the phrase About a questionnaire that clarifies the extent of understanding for the use of the Differentiated Education strategy, as the results showed that more than half of the study participants have general information about the strategy without depth. They do not distinguish between content and results and do not distinguish between strategy procedures, and most of them do not use it because it takes a long time in preparation and preparation. And there is no appropriate encouragement from management to use it

\section{Study Tools:}

In pursuit of the objectives of the study, the researcher used the following tools:

- Pre-test: The results of students were approved in the first month exam that the teachers prepared, applied, and monitored.

- Post test: in final form, the test consisted of (20) items of the multiple choice type with four alternatives and it was prepared by the researcher, and it was designed in order to measure the scientific achievement in the coordinate Geometry unit from mathematics for the ninth grade, after reading the behavioral objectives included in the unit in light of Bloom's classification In the cognitive domain, the unit content was analyzed into concepts, generalizations, skills and issues, and a table of test specifications was built.

\section{Test Validation:}

The objectives, the table of specifications and the test paragraphs were presented to five referees from among university professors specializing in curricula and teaching methods / mathematics, measurement and evaluation, and the referees were asked to place their observations on the test paragraphs in terms of their suitability to the concepts of the sixth unit of the ninth grade mathematics book entitled Coordinate geometry, and its linguistic and scientific formulation Then, some modifications were made in some drawings, some paragraphs and some alternatives were modified, and its final form consisted of (20) paragraphs, and the validity of the test was verified (appropriateness of content, and apparent validity).

\section{Test Stability:}

The test was applied to a neutral sample in a school in Amman. The study population consisted of (35) students from the ninth grade, and the reliability coefficient was calculated using the Coder-Richardson equation 20 (K20), and the stability factor was (0.83), and the difficulty values ranged The paragraphs are between $(0.38$ to 0.85 ), and the discrimination coefficients were calculated and were between (0.34 - 0.82). Therefore, the paragraphs were considered appropriate for the search procedures.

\section{The Limits of the Study:}

- Objective limits: The study was limited to the seventh unit: Geometric from the textbook for the second semester of the ninth grade.

- Human limits: The study tool was applied to students of three schools of the ninth grade students in special education schools: a neutral school on which the study tool was applied to calculate stability, and two schools, one experimental and the other controlling.

- Spatial Limits : Special education schools in the city of Amman.

- Temporal limits: This study was applied in the second semester 2019-2020.

\section{Procedural Definitions of Study Terms:}

- Differentiated Education Method of Teaching: an instructional strategy based on the teacher's innovation and its use of multiple 
teaching and evaluation methods and methods that take into account the individual differences that exist between students within the same class in order to provide them with equal opportunities for education according to their abilities and develop in the students life skills such as taking responsibility and active and positive participation.

\section{- The Usual (Traditional) Method of Teaching:} one of the teaching methods used in most schools, where the teacher presents the academic content according to what is stated in the textbook, and the teacher is often the only source of knowledge, and the student implements what the teacher requests to solve the questions of the book, and Homework review.

- Academic Achievement: It is a set of educational goals that are achieved by the student and is closely related to the mental ability to accomplish a specific action through sensory, mental and innate actions, this ability differs from one student to another, in this study Achievement means the set of scores that the student gets in the two tests( The pre-examination and postexamination in the Geometry unit)

\section{Study Procedures:}

- Coordination was made with two school administrations from the Private Education Schools in Amman to implement the study, one of which is an experimental group, and the second is a control group. The study tools was also applied in a neutral school.

- Two schools of special education were chosen intentionally, each of which contains two classes (male class and female class). One of the two schools was chosen as an experimental group and the other school as a control group.

- The nature of the male and female students in the experimental group was determined according to their levels of achievement (previous marks) in mathematics, and their preferences and personal characteristics based on the experience of the teacher and her colleagues who had previously taught the students.
The researcher made a guide for the teacher based on the use of the Differentiated Education strategy, as the guide included a description of the Differentiated Education strategy and the teaching plans based on the lessons, in addition to the working papers accompanying each lesson and the procedures to be followed by the mathematics teacher during the teaching of groups.

- The proposed guide and the teaching plans included in it were presented to a group of arbitrators, and their comments were taken.

- The teacher in the experimental group, who teaches both the male and female divisions, was trained to teach with the Differentiated Education strategy, with two sessions, and she was trained to use the strategy.

- Teaching was adopted in the traditional way in the control school, in which a male teacher and a female teacher taught in it, where lessons were prepared in the usual way.

- The test was applied to a neutral group from a third school in order to calculate the test reliability.

- The strategy was implemented during the second semester of the academic year 2018/2019, and its implementation took three weeks, with (4 classes

a week, a total of 12 classes).

- The post-achievement test was applied after the content was taught.

- Labels were collected and categorized, and descriptive and inferential statistical analyzes were performed using the SPSS statistical packages program.

\section{Study Variables:}

\section{- The Iindependent Variables:}

1 - Teaching Strategy and it has two levels:

a. Differentiated Education

B. Usual Method.

2- Gender with two levels:

a. Males.

B. Females.

- The Dependent Variable: the Post achievement of ninth grade students in mathematics in the coordinate Geometry unit, and it was measured by 
the test scores assigned to this unit for the students of the study sample.

\section{Statistical Treatment:}

- The arithmetic means and standard deviations of the students 'scores in the pre and post achievement exams were calculated.

- To test the hypotheses of the study, the results of the accompanying analysis of Two-way Analysis of Variance were used for the effect of teaching and gender strategies and the interaction between them on the achievement of ninth grade students in mathematics.

Study Population
The study population (members) were selected from the ninth grade students from two private schools in the city of Amman by intentional method, as each school contains two divisions, one for males and the other for females, which helped facilitate the process of data collection and implementation of the study, as indicated by the management of the two schools and teachers Mathematics includes the desire to cooperate with the researcher to implement the study procedures, and the number of study individuals has reached (106) male and female students distributed as the following table shows:

Table (1)

Distribution of group students on teaching strategies.

\begin{tabular}{|c|c|c|c|c|}
\hline the group & Type of strategy & Males & Females & Total \\
\hline Experimental & $\begin{array}{c}\text { Differentiated } \\
\text { Education }\end{array}$ & 24 & 18 & 42 \\
\hline Control & traditional way & 39 & 25 & 64 \\
\hline \multicolumn{2}{|r|}{ the total number } & 63 & 43 & 106 \\
\hline
\end{tabular}

The researcher has approved the results of the first month exams prepared by mathematics teachers during the second semester 2019/2020, and Table (2) shows the details of those results:

Table (2)

Number of students, Arithmetic Averages, and Standard Deviations of Students' Marks in the Preexam in Mathematics (Maximum Score of 30)

\begin{tabular}{|l|l|l|l|l|l|l|l|l|l|}
\hline \multirow{2}{*}{ Statement } & \multicolumn{3}{|l|}{ experimental group } & \multicolumn{3}{l|}{ Control group } & \multicolumn{2}{l|}{ Total } \\
\cline { 2 - 11 } & Male & Female & Total & Male & Female & Total & Male & Female & Total \\
\hline the number & 24 & 18 & 42 & 39 & 25 & 64 & 63 & 43 & 106 \\
\hline $\begin{array}{l}\text { Arithmetic } \\
\text { mean }\end{array}$ & 21.58 & 24.78 & 22.95 & 22.05 & 21.68 & 21.91 & 21.87 & 22.98 & 22.32 \\
\hline $\begin{array}{l}\text { standard } \\
\text { deviation }\end{array}$ & 8.21 & 8.54 & 8.41 & 6.66 & 8.23 & 7.25 & 7.22 & 8.41 & 7.71 \\
\hline
\end{tabular}

To make a comparison between these people and to ensure the equivalence of their members, a ttest was used for independent samples where the value of the calculated $t$ was $(t=0.00)$, at the level $(\alpha=0.05)$, which is a statistically significant value, which indicates the lack of parity between the two groups of the experimental and control study In terms of previous achievement in mathematics, which leads to the use of Analysis of Covariance ANCOVA analysis method, which takes into account the inequality between the two groups in the pretest.

\section{Results:}

The main question in this study was: What is the Effect of Using (Differentiated Education strategy 
and the Usual Method of Teaching) on Achievement in Mathematics? The arithmetic averages and standard deviations of the students' results in the post-test were calculated, and the following table (3) explains this:

Table (3)

Number of students, arithmetic averages, and standard deviations of students' marks in the PostAchievement exam in Mathematics (Maximum Score of 30)

\begin{tabular}{|r|r|l|l|l|l|l|l|l|l|r|}
\hline Statement & \multicolumn{3}{|c|}{ Experimental group } & \multicolumn{3}{c|}{ Control group } & \multicolumn{3}{c|}{ Total } \\
\hline $\begin{array}{r}\text { the } \\
\text { number }\end{array}$ & \multicolumn{1}{|c|}{ Male } & Female & \multicolumn{1}{|c|}{ Total } & \multicolumn{1}{c|}{ Male } & Female & \multicolumn{1}{c|}{ Total } & Male & Female & Total \\
\hline $\begin{array}{r}\text { Arithmetic } \\
\text { mean }\end{array}$ & 27.17 & 29.56 & 28.19 & 22.31 & 19.20 & 21.08 & 24.16 & 23.53 & 23.91 \\
\hline $\begin{array}{c}\text { standard } \\
\text { deviation }\end{array}$ & 8.17 & 8.52 & 8.31 & 6.01 & 8.10 & 7.01 & 7.24 & 9.68 & 8.29 \\
\hline
\end{tabular}

To answer the study's three questions and hypotheses, the researcher used the Two-way analysis of variance for the impact of teaching and gender strategies and the interaction between them on ninth grade students 'achievement in mathematics, where the results were as shown in Table (4) as follows:

Table (4)

Results of Two-way Analysis of Variance of the Impact of Teaching strategies and Gender and the interaction between them *

\begin{tabular}{|c|c|c|c|c|c|c|}
\hline Source & $\begin{array}{c}\text { Type III Sum of } \\
\text { Squares }\end{array}$ & df & $\begin{array}{c}\text { Mean } \\
\text { Square }\end{array}$ & F & Sig. & $\begin{array}{c}\text { Partial Eta } \\
\text { Squared }\end{array}$ \\
\hline Corrected Model & $5166.858^{\mathrm{a}}$ & 4 & 1291.714 & 64.072 & .000 & .717 \\
Intercept & 534.987 & 1 & 534.987 & 26.537 & .000 & .208 \\
exam & 3683.886 & 1 & 3683.886 & 182.729 & .000 & .644 \\
sex & 51.639 & 1 & 51.639 & 2.561 & .113 & .025 \\
school & 1057.945 & 1 & 1057.945 & 52.476 & .000 & .342 \\
sex * school & 45.085 & 1 & 45.085 & 2.236 & .138 & .022 \\
Error & 2036.199 & 101 & 20.160 & & & \\
Total & 67780.000 & 106 & & & & \\
Corrected Total & 7203.057 & 105 & & & & \\
\hline
\end{tabular}

a. R Squared $=.717$ (Adjusted R Squared $=.706$ )

The main question in this study was What is the Effect of Using (Differentiated Education strategy and the Usual Method of Teaching) on Achievement in Mathematics? Where the results of the statistical analysis were as follows:

The first question in the study was: Are there Differences between the Averages of Ninth Grade Students Achievement in Mathematics According to the Using Different Teaching Strategies (Differentiated Teaching and the Usual Method)?, and the null hypothesis associated with it was: There are no statistically significant differences (at $\alpha=0.05$ ) The average achievement of ninth grade students in mathematics attributed to the difference in the teaching strategy (Differentiated Teaching and the Usual method) Where the 
results were shown according to the probability value $(\mathrm{P}=.000)$, where the null hypothesis was rejected and the alternative hypothesis accepted, meaning that there are statistically significant differences at the level $(0.05=\alpha)$ between the averages of students 'achievement in mathematics in the post test between the experimental group and the control group in favor of the experimental Because it is the highest average (Effect Size: Partial Eta Squared $=.342$ )

As for the second question in the study: Are there Differences between the Averages of Ninth Grade Students Achievement in Mathematics According to gender (Male and Female)? In addition, its null hypothesis was: there are no statistically significant differences (at the level $\alpha=0.05$ ) between the averages of ninth grade students 'achievement in mathematics due to the difference in sex (male and female), as the results shown in Table(4) indicated that there were no differences. Significant according to the probability value ( $P$ $=.113$ ), where the null hypothesis was accepted, which states that there are no statistically significant differences (at $\alpha=0.05$ ) between the averages of ninth grade students 'achievement in mathematics in the post-examination due to the difference in sex (Male and female) in the mean achievement of students in mathematics in the post-test between males and females

And when analyzing the Third Question, which states: Is there an Effect of the Interaction between Teaching Strategies and Gender on Ninth Grade Achievement in Mathematics? its hypothesis was: There are no statistically significant differences (at the level $\alpha=0.05$ ) due to the existence of an interaction between the teaching strategy and gender in the achievement of ninth grade students in mathematics, as the results shown in Table (4) and after calculating the probability value $(\mathrm{P}=$ .138) by accepting the null hypothesis, that is, there is no effect of the interaction between the teaching strategy and gender statistically significant (at $\alpha=0.05$ ) on students 'achievement in mathematics in the post-test.

\section{Discussion the Results}

- The results of the study indicated the following that there are statistically significant differences at the level $(\alpha=$ 0.05 ) between the averages of students 'achievement in mathematics in the posttest between the experimental group and the control group in favor of the experimental because it has the highest average. The reason for this may be due to the nature of the differentiated teaching strategy that It takes into account individual differences, and that the teaching position is mixed with feelings of suspense, motivation, challenge and sequence in skills, which attracts the student towards the educational material, and is positive in the teaching position, and the student exerts mental effort through the various educational activities that have been applied, and the teaching plans prepared by him Researcher in the Geometyy unit

- Where he focused on the clear use of drawings and geometric shapes, as well as the nature of questions that require thinking according to the level of the student within his group, and encouraging students to ask more questions. The results of the study were in agreement with the results of both (Airss, 2017), (Rahma, 2017) (Al-Ali, Al-Mahrezi, 2017), (AlNabhan, 2016), (Morsi, 2015), (Al-Raei, 2014).

- The results indicated that there was no effect of gender in the achievement of ninth grade students in mathematics, which reinforces that students possess the same Geometric and mathematical skills, regardless of gender, and this study is considered one of the few studies that have studied this variable. 
- With regard to the absence of a statistically significant interaction between teaching strategy and gender, as this can be attributed to the fact that the use of cooperative learning groups while solving problems is consistent with contemporary trends in developing thinking skills and increasing achievement. Thinking is no longer a personal activity linked to gender and social level, but it has become an activity that includes all Male and female students have almost the same conditions, economic and social level, and the number of classes, so neither group was affected by the gender factor.

\section{Recommendations and Proposals}

In light of the findings of the current study, the researcher recommends the following:

- Training mathematics teachers on how to teach using the Differentiated Education strategy.

- Organizing the content of mathematics textbooks in a way that allows the teacher to use the Differentiated Education strategy.

- Organizing the student's cumulative record in a neighborhood that contains data on his cognitive, psychological and social status in addition to his level of achievement, the problems he suffers, and his distinct qualities for reference when building Differentiated Education plans.

- Conducting more quantitative and qualitative research aimed at knowing the effect of using the Differentiated Education strategy and other variables.

\section{References:}

[1] Al-Helisi, Moeed Hassan. (1433). The Effect of Using Differentiated Education Strategy on Academic Achievement in the English Language Course for Sixth Grade
Primary Students, Makkah AlMukarramah, Unpublished Master Thesis, College of Education, Umm AlQura University, Makkah Al-Mukarramah.

[2] Al-Barakati, Nevin (2018). A proposed training program based on enjoyable learning strategies for primary school mathematics teachers in Makkah in light of the reality of their training needs. Journal of the Faculty of Education at Al-Azhar University, Issue (177, Part Two), January

[3] Al-Tuwairqi, Hanan Muhammad. (2013). Differentiated teaching and its impact on motivation, thinking and academic achievement, Khwarazm Scientific Library, Jeddah.

[4] Al,Alie, Yahya; Muzaffar, Muzaffar; Mahdi, Abdullah. (2017) The effect of using the Differentiated Education strategy in teaching mathematics on achievement and self-concept among primary school students in Hajjah Governorate, Faculty of Education - Assiut University, The Scientific Journal of the College of Education, Volume 33, Issue 2.

[5] Al-Rehaily, Youssef (2012). The effect of using the Differentiated Education strategy on achievement and the trend towards science for second-grade intermediate students, an unpublished master's thesis, College of Education, Taibah University.

[6] Al-Mahdawi, Fayez Abdel-Karim (2014). The effect of using the Differentiated Education strategy on developing the achievement of the biology course among secondary school students. Unpublished MA Thesis, College of Education, Umm Al-Qura University, Makkah AlMukarramah.

[7] Al-Nabhan, Muslim (2016). The Effectiveness of Teaching Using the Educational Pillars and Differentiated Education Strategies in the Achievement of Intermediate Second Grade Students in Physics, Unpublished Master Thesis, 
College of Education, University of AlQadisiyah.

[8] Al-Rahi, Amjad (2014). The effectiveness of Differentiated Education strategy in teaching mathematics on the acquisition of mathematical concepts and the tendency towards mathematics among students of the seventh grade basic, an unpublished master's thesis, College of Education, Islamic University - Gaza.

[9] Ariss, Laila D.(2017). Differentiated Instruction: An Exploratory Study in a Secondary Mathematics Classroom, 'As partial fulfillment of the requirement for the Doctor of Philosophy Degree in curriculum and Instruction, The University of Toledo

[10] Attia, Mohsen Ali. (2009). Comprehensive and new quality in teaching. Amman, Safaa House for Publishing and Distribution.

[11] Attia, Mohsen Ali (2009). Modern curricula and teaching methods. Amman, House of Curriculum for Publishing and Distribution.

[12] Bassiouni, Fayza Abdel Salam (2013). Elearning, Umm Al-Qura University, Makkah.

[13] Campbell,B. (2008). Handbook of differentiated Instruction Using the Multiple Intelligences lesson Plans and More, Boston : Pearson Education, Inc

[14] Joseph , S. (2013). Differentiating Instruction: Experiences of Pre-Service and- In-Service Trained Teachers. Caribbean Curriculum, Vol. 20, , pp31-51

[15] Kojak, Kawthar Hussain and others. (2008). Diversifying Classroom Teaching A teacher's guide to improving methods Teaching and learning in schools in the Arab world, Beirut, UNESCO Regional Office for Education in the Arab Countries.

[16] Morsi, Hatem. (2015) The effectiveness of differentiated teaching approach in science teaching on the development of scientific concepts and the trend towards science among elementary school students in the Kingdom of Saudi Arabia, Journal of Scientific Education - The Egyptian Society for Scientific Education, Volume 18 , Issue 1, January.

[17] National Center for Human Resources Development. (2017). Jordan National Report on International Mathematics and Science Study 2015 (TIMSS 2015), 183 Center Publication Series, Jordan.

[18] Obaidat, Thouqan and Abu Al Semeed, Suhaila. (2007). Teaching Strategies in the Twenty-first Century: A Teacher's Guide and Educational Supervisor. Amman, Dar Al-Fikr for printing, publishing and distribution.

[19] Rahma, Areej Nafez (2017). The effect of employing differentiated teaching on developing mathematics skills and the direction towards them, an unpublished master thesis, College of Education, Islamic University - Gaza.

[20] Tomlinson, Carol A.(2016). The differentiated classroom : responding to the needs of all learners, Second edition. ASCD, 1703 N. Beauregard St., Alexandria, VA 22311-1714 USA. 